Rapid Reviews COVID-19

\title{
Reviews of "Obesity may hamper SARS-CoV-2 vaccine immunogenicity"
}

Jonathan Hare ${ }^{1}$, Carlota Dobaño ${ }^{2}$

${ }^{1}$ IAVI, ${ }^{2}$ ISGLOBAL: Instituto de Salud Global de Barcelona, Malaria, Spain

Published on: May 07, 2021

License: Creative Commons Attribution 4.0 International License (CC-BY 4.0). 
To read the original manuscript, click the link above.

Summary of Reviews: This paper presents potentially important information about the effects of obesity on vaccine immunogenecity, but reviewers find that the analysis needs substantial clarification and the claims should be presented in the context of the lack of clinical outcomes data.

\section{Reviewer 1 (Jonathan Hare)}

\section{Reviewer 2 (Carlota Dobaño)}

\section{RR:C19 Strength of Evidence Scale Key}

$$
\begin{aligned}
& \text { प }
\end{aligned}
$$

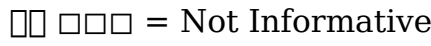

$$
\begin{aligned}
& \text { प्रा पि = Potentially Informative }
\end{aligned}
$$

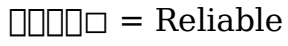

$$
\begin{aligned}
& \text { प्राप्र = Strong }
\end{aligned}
$$

To read the reviews, click the links below. 